\title{
Instructional Design for the Information and Communication Technology (ICT)-Assisted Intercultural Communication Course
}

\author{
https://doi.org/10.3991/ijet.v12i06.7083 \\ Yu-Chih Doris Shih \\ Fu-Jen Catholic University, New Taipei City, Taiwan \\ dshih@mail.fju.edu.tw
}

\begin{abstract}
Today's era of societies comprise of one coherent global village, in which learning about and understanding other cultures is crucial. Fu-Jen Catholic University (FJCU), a private university in northern Taiwan, has joined the "Global Academic Initiatives" (GAI) coordinated by East Carolina University (ECU) in USA since 2007. A course entitled Cross-Cultural Communication: Global Understanding is offered in FJCU to allow students in the English department to discuss cultural topics with students from two other countries via Information and Communication Technologies (ICTs) for authentic contacts. The ICT tools support both the synchronous and asynchronous mode of communication. This paper describes the instructional design of the Cross-Cultural Communication: Global Understanding course including the pre-connection trainings and the connection discussions. For the post-connection part, students' learning and reflections will be discussed along with their e-learning styles. This example could offer other educators who are interested in designing similar intercultural communication courses.
\end{abstract}

Keywords-Intercultural communication, Information and Communications Technology (ICT), Instructional design, Taiwanese college students

\section{Introduction}

In this day and age of global villages, cultural empathy and understanding are of great importance, as one comes in contact with people of various backgrounds frequently, either for the purposes of learning and teaching or business communication. With a variety of digital media appropriate for teaching and learning, without a doubt, Information and Communication Technologies (ICT) currently play an important role in intercultural communications and learning [1]. This paper describes the instructional design of the Cross-Cultural Communication: Global Understanding course offered by the Department of English Language and Literature in Fu-Jen Catholic University (FJCU) in Taiwan, which joined the "Global Academic Initiatives" (GAI) coordinated by East Carolina University (ECU) in USA since 2007. Students in this course are given the opportunity to experience authentic contacts with counterparts 
Paper-Instructional Design for the Information and Communication Technology (ICT)-Assisted Inter...

from several foreign countries and discuss cultural issues of the different cultures. Through ICT tools, students are also able to learn through situated learning.

\section{About the Course}

The education system in Taiwan is based on semesters. Both the Fall and Spring semesters are 18 weeks long. Before the actual international connections, there are local sessions for the instructor to prepare the learners for intercultural interactions. As a tradition of all courses taught in the English department of FJCU, everything is conducted in English only. Then, the class connects with two to three different countries separately. For the past few years, the first country was usually USA with students in ECU. The second and third country could be Mexico, Peru, Switzerland, Russia, or Japan, depending on how ECU designs the master schedule (The third country may connect for two or three weeks only instead of four full weeks depending on the date of the end of the semester in Taiwan).

Each of these international connection sessions lasts around 100 minutes. The class is divided into two groups (A and B), with one group talking to their counterpart via large-group interactive videoconference the first 45 to 50 minutes, while the second group texts with their partners one-on-one using a text-chat IRC program such as IceChat or Kiwi via the server of ECU (and if there are problems, FaceBook Messenger or Google Hangout could be used). In the second 45 to 50 minutes, the groups then switch their methods of communication. A teaching assistant is present during class time to help with the text-chat issues. Also present is a technician at the back of the classroom in the Taiwan end (in a technical booth) that is a distance learning room equipped with videoconferencing system and video recording facilities (See Table 1 for the short version of the schedule in the course syllabus).

Along with the syllabus, a course map is drawn by the mind map software Inspiration to be uploaded to the Learning Management System, EngSite, for the students (see Fig. 1 for the course map). According to the requirement by FJCU, Professional Knowledge and Professional Skills need to be listed properly for each course. Under Professional Knowledge, cultural knowledge (both local and foreign cultures), communication theories and strategies, as well as cross-cultural communication methods are mentioned during local training sessions. For the Professional Skills, "Advanced English Expressions" through the four language skills (English reading, writing, listening, and speaking), "Problem solving," and "Information Technology" are included. Overall, the instructor intends to provide the learners the opportunity to learn and achieve the following through this course: cultural knowledge, intercultural communication skills, intercultural competence, and ICT skills. These objectives match the educational goals of the department. They are also important as [2] pointed out, "If our goal is to prepare students for positive intercultural participation through effective communication, students need not only to make themselves understood, but also to be accepted behaviorally and interactionally, especially because acceptance is more often strained by offending behaviors than by incorrect grammar" (p. 11). 
Table 1. A sample schedule of the course (short version)

\begin{tabular}{|c|c|l|}
\hline Week & Mode & \multicolumn{1}{|c|}{ Activities } \\
\hline 1 & Local & Introduction; about Global Understanding Project; Culture and Communication Concepts \\
\hline 2 & Local & Learn text-chat programs; Video: "Cross-cultural Communication"; Cultural sensitivity \\
\hline 3 & Local & $\begin{array}{l}\text { Issues of cyber communication; Introduction to cultural theories: Hofstede Theory and } \\
\text { Lewis Model }\end{array}$ \\
\hline 4 & Local & Guest speech: Indian Culture \\
\hline 5 & Connect & Connection with country A: Lecture; College life \\
\hline 6 & No class & Spring break: No Class \\
\hline 7 & Connect & Connection with country A: Family; Cultural Traditions \\
\hline 8 & Connect & Connection with country A: Meaning of Life and Religion; Stereotypes and Prejudices \\
\hline 9 & Connect & Connection with country A: Collaborative Project Presentations on donation topic \\
\hline 10 & Local & Individual conference with the instructor: Talk about your collaborative projects progress \\
\hline 11 & Connect & Connection with country B \\
\hline 12 & Connect & Connection with country B \\
\hline 13 & Connect & Connection with country B \\
\hline 14 & Connect & Connection with country B \\
\hline 15 & Connect & Connection with country C \\
\hline 16 & Connect & Connection with country C \\
\hline 17 & Connect & Connection with country C \\
\hline 18 & Local & Oral Presentation \\
\hline
\end{tabular}

\section{Instructional Design}

Based on a previous study report done by the author [3], the following tips of instruction are adopted for the design of this intercultural communication course based on the cross-cultural comparison of learning styles of Asian learners to learners of other cultural backgrounds:

1. Provide the outlines for the overall course and for each of the connections since the Asian learners are mainly holistic learners (Asian students are even less analytic when compared to Africans or learners of other cultural backgrounds).

2. Provide concrete examples when discussing abstract concepts (Asian learners have a lower preference of abstract learning when compared to Africans).

3. Give step-by-step guidance in the instructions, since Asians in Taiwan have a higher preference in sequential learning.

4. Asian learners are low in Persistence learning style (i.e., Mdn= 2.67 out of 5.00). Therefore, audio, animations or video clips should be kept short since they have shorter attention span.

5. Asian learners have a lower preference in Learning with Group when compared to African learners. However, instructors must promote team-learning and collaboration since this is an essential concept nowadays. The inclusion of Collaborative project done by students of different countries in the Global Education project is a good practice for these learners.

6. Asian learners have a lower preference in Text learning style (reading of text materials). However, to be able to read and understand texts is a crucial skill, especially for academics in higher education. Instructors can provide shorter and various articles for reading materials. 


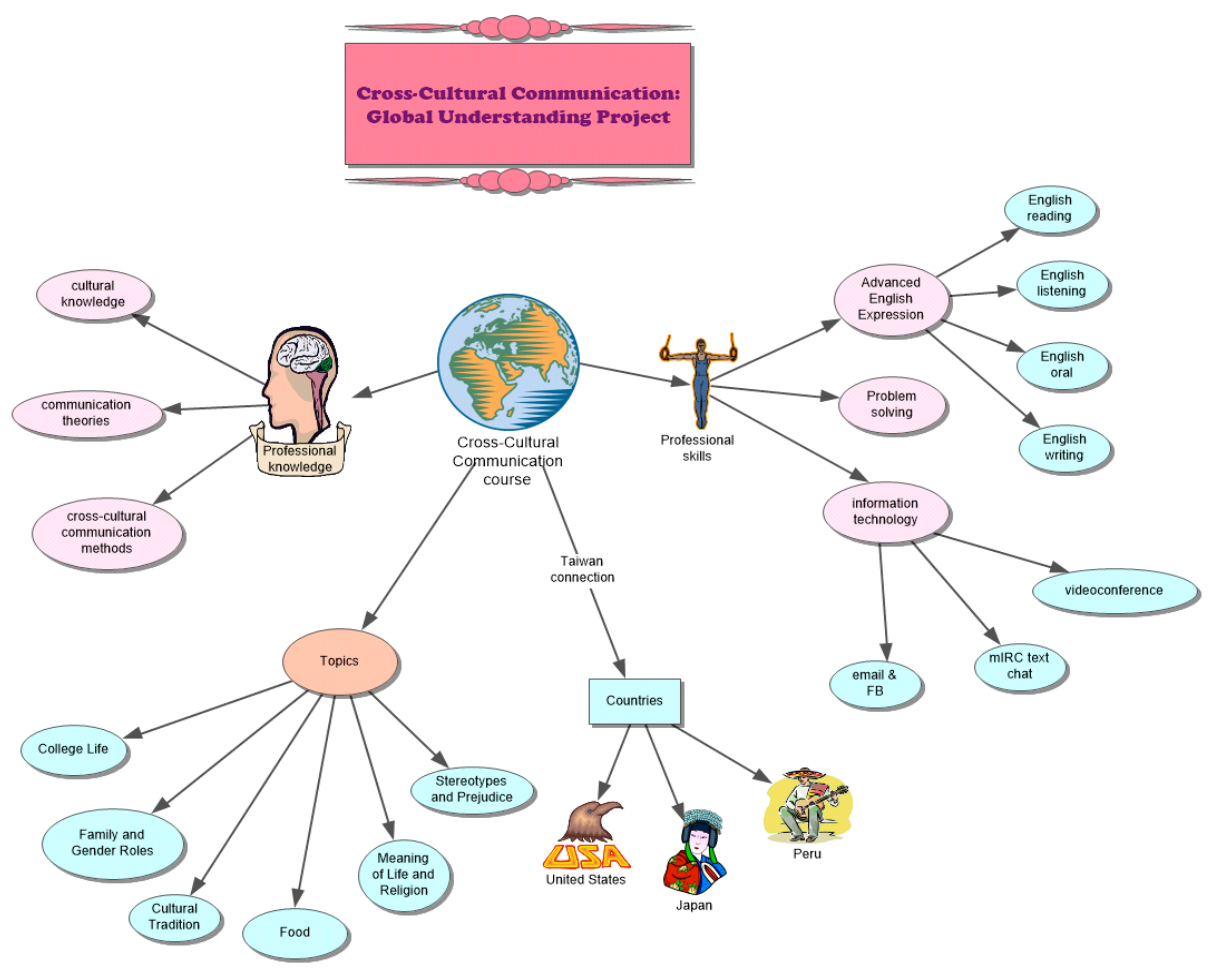

Fig. 1. The course map for the intercultural communication course

Consequently, the course of intercultural communication are categorized into several phases, including the pre-training phase, international connection phase (focusing on the discussion of several topics), collaborative project phase, and post-connection phase. In the pre-training stage, the instructor goes through cultural theories such as Hofstede's cultural dimensions [4], shows the DVD video of "Cross-Cultural Communication: How Culture Affects Communication," discusses etiquettes and issues on cyber-communication [5], and finally, completes the training on using online text-chat programs. Students are able to explore their e-learning styles as well.

After the pre-training stage and during international connection sessions, the FJCU teacher and the students have three to four week's connection with foreign partners in two to three countries. The first connection session starts with the instructors' lecture from both countries followed by the students' brief self-introduction. The instructor's lecture about Taiwan include the demographical background information as well as the interesting activities in the night markets and their meaningfulness to the Taiwanese. Then, as for the rest of the sessions, topics for discussion and learning about other's culture include "College life," "Family and Cultural Tradition," "The Meaning of Life and Religion," "Stereotypes and Prejudices," and the "Free topic" session. The free topic session could be devoted to the presentation of the collaborative project of students of both sides. 
The instructors of each countries discuss and come up with a general guideline about the collaborative project for the participating students at the beginning of the connection, so that students would have enough time to work on their team project for presentation. Choices on the topics of collaborative project may be given, for example, "The meaning of Success," "A role model in one's country," "How to help people with 1 billion dollars?" etc. Instructors of both sides may also ask students of both countries to prepare for role-plays or to perform their traditional dances and rituals in the connection. Throughout the semester, students in Taiwan write short journals to reflect on their connections. After the connections, they give a final presentation and write a term paper on the comparison of the cultures.

\section{$4 \quad$ Students' Learning and Reflections}

In one semester for pilot testing, thirteen English-major students in a class connected with students in Mexico, Peru, and Japan (There were some exchange students from other foreign countries excluded for data analysis). The Online Learning Style inventory (by Liu \& Shih as explained in the paper of [6]) and post-connection surveys (Peru survey, Mexico survey, and Japan survey) were given to the students in Taiwan to fill out to examine their e-learning styles and the feasibility of the connections. Quantitative and qualitative data analyses were conducted for analysis.

Table 2. Results of Online Learning Styles of English majors in Taiwan (N=12)

\begin{tabular}{|c|c|c|c|c|}
\hline \multirow{2}{*}{\multicolumn{2}{|c|}{ Learning Styles }} & \multicolumn{2}{|c|}{ Descriptive Data } & \multirow[t]{2}{*}{ Other Statistics } \\
\hline & & Mean & $S D$ & \\
\hline \multirow{4}{*}{ Perceptual } & Text & 3.40 & .48 & \multirow{4}{*}{$\begin{array}{l}\text { One-way repeated measure ANOVA: } \mathrm{F}(3 \text {, } \\
32.05)=.69, \mathrm{p}=.56\end{array}$} \\
\hline & Visual & 3.67 & .60 & \\
\hline & Auditory & 3.52 & .73 & \\
\hline & Active & 3.67 & .50 & \\
\hline \multirow{6}{*}{ Cognitive } & Abstract & 3.27 & .39 & \multirow[t]{2}{*}{ Paired t-test: $\mathrm{t}(11)=-3.13, \mathrm{p}=.01^{*}$} \\
\hline & Concrete & 3.92 & .57 & \\
\hline & Serial/Linear & 3.61 & .62 & \multirow[t]{2}{*}{ Paired t-test: $\mathrm{t}(11)=-.53, \mathrm{p}=.61$} \\
\hline & Random & 3.48 & .56 & \\
\hline & Holistic & 3.42 & .48 & \multirow[t]{2}{*}{ Paired t-test: $\mathrm{t}(11)=-1.06, \mathrm{p}=.31$} \\
\hline & Analytic & 3.24 & .39 & \\
\hline \multirow{5}{*}{ Personality } & Study Alone & 3.58 & .46 & \multirow[t]{2}{*}{ Paired t-test: $\mathrm{t}(11)=-.57, \mathrm{p}=.58$} \\
\hline & Study with Group & 3.48 & .31 & \\
\hline & Guided & 3.52 & .76 & \\
\hline & Persistence & 2.61 & .85 & \\
\hline & Observer & 3.04 & .45 & \\
\hline
\end{tabular}

Note: ${ }^{*} p<.05$

For the quantitative data, the reliability results of the online learning styles inventory is medium with a Cronbach's $\alpha$ of .40. This is because of the small number of sample (only twelve students filled out this inventory). For the descriptive outcomes (Means and Standard deviations) of the different types of online learning styles, please see Table 2. The test of normality showed non-statistical significance (using Shapiro-Wilk's test), which meant parametric tests could be adopted for further anal- 
yses. We saw that the four perceptual learning styles of this group of students were about the same. A one-way repeated measure ANOVA result revealed a nonstatistical significant effect, $F(3), 32.05)=.69, p=.56$. No post-hoc analysis was needed in this case.

For the pairs of cognitive learning styles and personality learning styles, paired $t$ tests showed that only the pairs of Abstract vs. Concrete learning styles had a difference, $t(11)=-3.13, p=.01$. Learners were more concrete-oriented $(M=3.92 ; \mathrm{SD}=.58)$ than abstract-oriented $(M=3.27 ; \mathrm{SD}=.39)$ (see Table 2$)$. The results gave a good support for the instructional design of the course by providing concrete examples and materials for students in this course.

From the qualitative responses in the post-connection surveys, we witnessed the self-awareness and reflections of the learners. Participants especially mentioned the difficulties in understanding the accents of Mexicans and Peruvians (Student 5 and Student 12 in the Peru survey). However, they gave their best efforts, rose to the challenge, and eventually grew accustomed to the accents. Some brought up the limitations related to technology, Student 6 said "What I disliked was that sometimes few people are seen on the screen" (Peru survey).

As for comparison of working with people of different cultures, Student 10 mentioned about the need of efficiency because of working under a different time zone, “...when I was working with my partner, the time difference did not allow us to chat a lot. We need to be more efficient and straight to the point." (Mexico survey). During the connection with the Japanese partners, Student 2 pointed out the efficient work ethics of the Japanese student, and found that they were constantly comparing the similarities of Taiwanese culture versus Japanese culture, since both belong to the classification of Asian culture. However, there were some variances; Student 4 learned some parts of the Japanese culture that she did not know, such as the eating of horse meat. Besides the survey data results, one could see through observations of the course that the students were very active in discussing the cultural topics through large-group videoconference orally as well as the one-on-one text-chat (See Fig. 2 for a photo of the videoconferencing group in the distance learning classroom).

\section{Conclusion}

In this paper, the instructional design of the course, Cross-Cultural Communication: Global Understanding, offered at FJCU was explained first. Learners' online learning styles and post-connection survey data were collected from the students in the course prior and after the international connections in one semester. The descriptions and findings provided in this paper would be valuable to other educators who conduct similar cross-border cultural learning or intercultural telecommunication projects. 


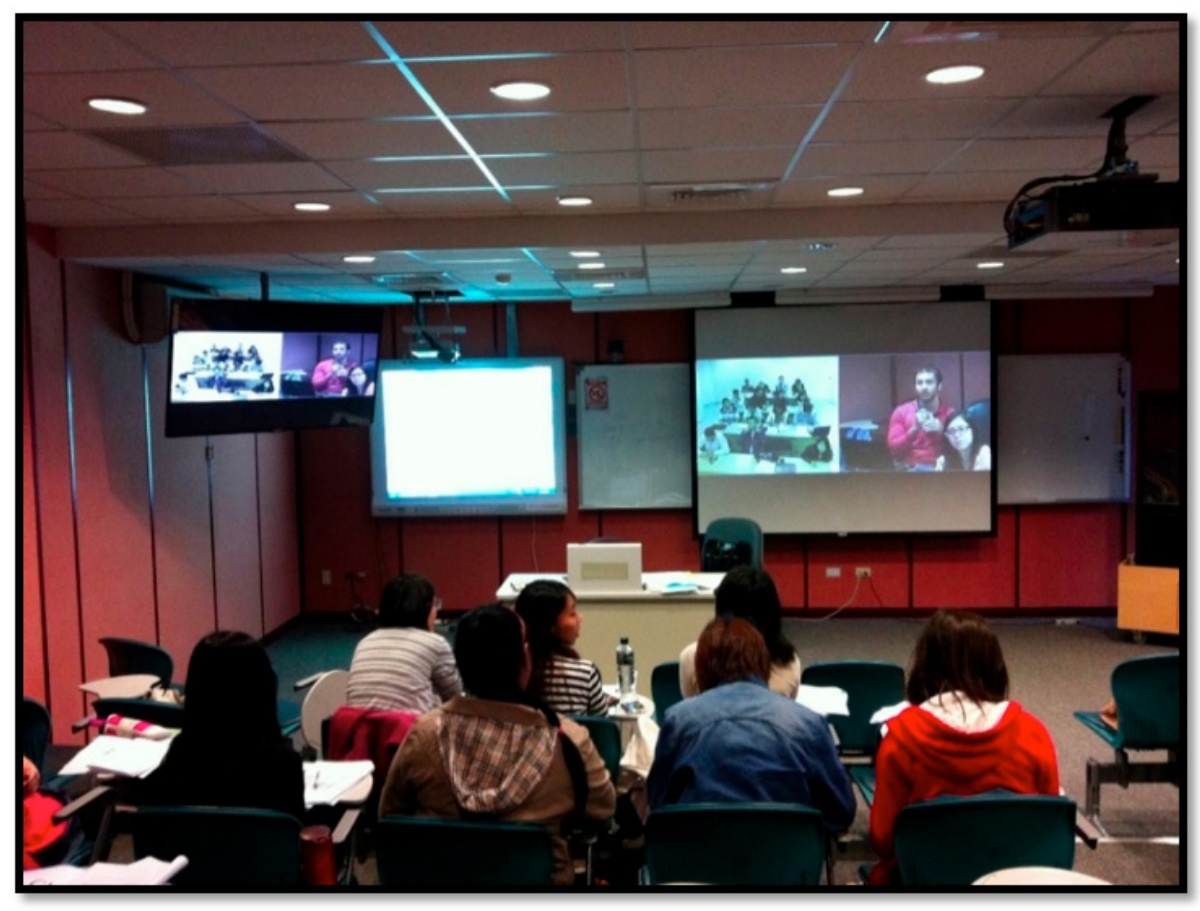

Fig. 2. A photo of the videoconferencing group.

\section{Acknowledgment}

The project described in this paper being conducted in the current academic year (2016-2017) is supported by the Ministry of Science Technology in Taiwan (MOST 105-2410-H-030-051).

\section{$7 \quad$ References}

[1] E. Hassim and M. Peucker, "Using ICT in schools to foster the development of students' Asia capabilities - What works," Primary \& Middle Years Educators, vol. 11, no. 3, pp. 13-21, 2013.

[2] A. E. Fantini, "Expanding the goal of ESOL," Essential Teacher, vol. 5, no. 1, pp. 11-12, Mar. 2008.

[3] Y-C. D. Shih, "A cross-cultural comparison of e-learning styles,"paper presented at 2017 International Conference in Applied Linguistics and Language Education (ICALLE 2017), De La Salle University, Manila, Philippines. February 10, 2017.

[4] G. Hofstede, G. J. Hofstede, and M. Minkov, Cultures and Organizations: Software of the Mind (3rd ed.). New York, NY: McGraw-Hill, 2010.

[5] Y-C. D. Shih, Videoconferencing for the Learning of English Language and Culture. Taipei, Taiwan: Fu-Jen Catholic University Press, 2007. 
Paper-Instructional Design for the Information and Communication Technology (ICT)-Assisted Inter...

[6] Y-C. Liu, Y-C. D. Shih, and Z-W. Yeh, "The development of Online Learning Styles Inventory: An exploratory study," The International Journal of Cyber Society and Education, vol. 3, no. 2, pp. 99-116, 2010.

\section{Author}

Yu-Chih Doris Shih is an Associate Professor in the Department of English Language and Literature, Fu-Jen Catholic University, New Taipei City, Taiwan. Her research interests are in the areas of English language and cultural learning with technologies, instructional design, multimedia education, and distance learning.

Article submitted 29 April 2017. Published as resubmitted by the author 13 June 2017. 